\title{
A CRITICAL REVIEW
}

\section{THE PATHOLOGY OF CEREBRAL GLIOMAS}

\author{
BY \\ H. J. SCHERER \\ From the Department of Pathology, Bunge Institute, Antwerp, and Centre of Tumour \\ Research, University, Ghent
}

A CRITICAL review of the historical development and the present state of the pathology of cerebral gliomas is justified for different reasons. The first is the frequency of the condition : over 1 per cent. of all deaths are due to intracranial tumours (Ewing, 1928 ; Weil, 1934 ; Cox, 1935 ; Greenfield, 1936 ; Courville, 1937 ; Flock, 1937), about half of which are gliomas (Tooth, 1912, and all following authors). According to Peers (1936), intracranial tumours form 16.8 per cent. of all malignant neoplasms in man. Secondly, the number of papers written on this question during the last 50 years and the frequent contradictory opinions, make it almost impossible to reach a clear conception without an intimate acquaintance and an extensive personal experience of the subject. Thirdly, the whole glioma literature of the last 15 years practically ignores the previous work to such an extent that many previously well-established facts have completely been forgotten or often rediscovered in good faith by authors who believe that there was no worth-while glioma research before Bailey and Cushing (1926). Fourthly, the evolution of investigations on gliomas is extremely instructive from a general point of view : it demonstrates clearly that the study of a natural phenomenon transforms itself into sterile discussions as soon as the methods and principles generally applied in natural sciences are replaced by predominantly scholastic methods more devoted to the establishment of names, classifications, statistics, and theories than of facts. Finally, some recent developments of glioma research justify the hope that in the near future it will emerge from the deadlock of interpretations in which it has struggled for about 20 years and will become again a fruitful branch of natural sciences.

To contribute to this evolution is one of the essential purposes of this paper. This purpose determines both the form and content of the review. Owing to the limited space, it is impossible for the review to be complete. It has to deal essentially with the historical evolution of our knowledge of facts, but not with the creation of new names and systems for things known before under other names. This philological aspect of the question will be considered only in so far as it is necessary to understand the evolution of the glioma problem. Strong 
criticism has the object of impeding continuous waste of time and material by researches the uselessness of which is evident. Especial weight shall be given to the author's researches carried out during the last 8 years on 130 gliomas obtained at necropsy. These were studied by a new method allowing a particularly complete examination of the tumours.

\section{The Classical period of Glioma Research}

Gliomas with their macroscopical resemblance to normal brain tissue (Burns, 1800) were known long before Virchow; by the English under the name of " medullary sarcoma" (Abernethy, 1804), as " encéphaloïde" by the French, and by German authors as "fungus medullare." This was the period of macroscopical research. Virchow (1863/1865) not only created the name "glioma" but-what is much more important-he opened the period of combined macroscopic and microscopic study of these neoplasms. He distinguished two main groups of brain tumours, glioma and sarcoma, the latter term having for him not a histogenetic but a purely descriptive sense. He characterized gliomas as follows : these are often enormous tumours of brainlike appearance with very slow clinical evolution; never showing a clear limitation towards the normal brain tissue, but resembling more a hypertrophy of the involved parts (the general architecture of which seems preserved) than real neoplasms. Microscopically they are formed by a proliferation of glia cells and sometimes of glia fibres : in the latter case, the tumour is rather hard ; in the former soft. Owing to extensive vessel proliferations or " myxomalike" degeneration in these tumours, he still distinguished "teleangiectatic" and " myxogliomas." Although his histological study was handicapped by the immaturity of the histology of that day, his general description very clearly characterizes the tumour known to-day under the name of "cerebral astrocytoma"; he even emphasized the occasional coexistence of quite variable histological structures in one and the same tumour. His cerebral sarcomas have the following characteristics : as opposed to the gliomas, they frequently have a spherical shape and definite boundaries, but they sometimes show also a more imperceptible transition towards the surrounding tissue. Extensive hæmorrhages often provoke an "apoplectic" clinical evolution. Microscopically they are distinguished from the gliomas by their high cellularity and much larger, often fusiform, shape of cell, by their high vascularity and pronounced fatty degeneration. There is no doubt that these tumours correspond to what is now called "glioblastoma." Thus, the clinical and pathological differences between the two main groups of brain tumours which dominate all modern glioma classifications had been perfectly characterized in 1865 . Recent systematic researches (Scherer, $1940 a, b$ ) have entirely confirmed Virchow's description of the general pathology of these groups, while the modern, essentially cytological systems have replaced many previously clear notions by considerable confusion.

The methods and findings of Virchow are still of the greatest importance. The method is that of the objectively described, combined macro- and micro- 
scopical study, giving in principle the same weight to the macroscopical aspect -forms of growth and extension, general architecture, structural variations from one place to the other, degenerative lesions, and clinical course-as to merely cytological investigations. He determined the methods of glioma research for about 50 years. The undoubted poverty of Virchow's histological descriptions and the tremendous progress realized by histology during this period explain why the histological point of view has become more and more predominant since the beginning of this century. Unfortunately, the slowly increasing custom of neglecting other aspects of gliomas in favour of cytological studies is accompanied by the tendency to violate or neglect facts in favour of preconceived ideas or systems based on the study of isolated aspects of glioma pathology. Let us follow now the steps of this evolution of methods, knowledge, and ideas.

Stroebe's (1895) work furnishes the first really detailed microscopical description of gliomas, and this fact certainly has more importance than the theoretical discussions and errors of interpretation found in his paper. $\mathrm{He}$ confirmed the essential differences of macroscopical behaviour and mode of growth between "glioma " and " sarcoma" as described by Virchow. He was the first to use new "specific" methods for the staining of the different histological structures. But-in contrast to most modern investigators, hypnotized by such methods-he did not neglect a careful study of all other aspects of his cases. He never limited his histological study to an arbitrarily chosen fragment of glioma tissue, but always examined very large parts of the tumours by means either of large celloidin or of numerous small paraffin sections whose exact location in the tumour was indicated. Thus, he discovered that pre-existent nerve cells and fibres are conserved in the midst of glioma tissue, though not in " sarcomas" ; that the leptomeninges are invaded by " sarcomas," but not by gliomas ; the existence of circumscribed "sarcoma" nodules in otherwise typical gliomas ; the frequent small cystic degeneration in "gliomas"; the existence of numerous glial fibres in " gliomas," their absence in "sarcomas"; the absence of mitoses and highly polymorphous cells in the former, their frequency in the latter ; the essentially infiltrative growth type of "gliomas," using the pre-existent fasciculation of nerve fibres, which modifies the otherwise round shape of the tumour cells to an elongated one. This important notion that the cell form in gliomas may depend upon mechanical influences exercised by the pre-existent brain tissue has been entirely forgotten by most modern writers, who implicitly consider the forms of glioma cells as an exclusively intrinsic factor of " histogenetic" significance.

Henneberg (1897) and Storch (1899) confirmed Stroebe's description in all essential points, except for the differential significance of glial fibres. While Stroebe excluded the diagnosis of a "glioma " in the absence of glial fibres and "spider-cells" (= fibrillary astrocytes), Storch emphasized that gliomas have the same property as all other tumours to become so atypical that no more typical structures (e.g. fibres) are formed. In such cases he considered the entirely diffuse, unlimited growth type as sufficiently specific to justify in itself the diagnosis of a "glioma." Here we see the implicit transition of the purely 
descriptive sense of these names into a definite "histogenetic" sense : for Virchow, sarcoma in the brain and elsewhere meant nothing but a tumour of a given macroscopic and cellular aspect; since the end of last century, it has meant tumour of mesenchymal origin. Glioma research began to leave the field of facts and entered that of deduction. Most papers of the following 10 years tried to fix the histogenetic position of the brain tumours previously called " sarcomas," and to prove their glial character in spite of the absence of glial fibres. These tumours became known as "gliosarcoma" (Borst, 1902) or "glioma sarcomatodes" (Stumpf, 1911), terms which do not suggest a combination of glial and mesenchymal tumours, but a tumour of purely glial " histogenesis" whose morphology resembles a sarcoma. All further discussions deal with the recognition by morphological methods of the glial histogenesis of a tumour, whose cells do not resemble glia but a (mesenchymal) sarcoma (Ranke, 1911). For a long time (Stumpf, 1911) the growth by diffuse infiltration superimposed on the persisting and pre-existing structures remains the essential criterion for glial tumours of typical or atypical ("sarcomatous") cellular aspect.

In 1899 Storch clearly described for the first time a brain tumour whose general morphology differed from both the main groups known until then. In a child of 6 years he found a partially cystic tumour of the parietal lobe characterized by a curious papillary perivascular structure, its cells forming " crowns of rays" around the vessels, and in other places tubular structures with a lumen, resembling the central canal of the nervous system. There is no doubt that this is the first description of what is to-day called an "ependymoma." Storch even desribed 3-4 dark corpuscles in the cytoplasm of the tumour cells, which in all probability correspond to the " blepharoplasts" considered as so important for the diagnosis by Mallory (1902) and Bailey (1924). Saxer (1902), Mallory (1902), and Muthmann and Sauerbeck (1903), in masterpieces of careful, methodical, and objective descriptions, created the complete picture of this tumour group. In 1903 the following was known about these tumours : they are distinguished from the other primary brain tumours by an exclusively expansive growth ; they are lobulated and papillary tumours, comparable to intracanalicular fibro-adenomas of the breast (Muthmann and Sauerbeck); three structures are encountered : the perivascular "crowns," the cavities lined by ependymal cells, and more cellular parts. Necrosis and calcification of vessels (Saxer) may be present. These tumours are frequently located in the ventricular cavity, especially in the IVth ventricle, but occur also outside the ventricles, in the brain hemispheres (Storch, 1899 ; Saxer, 1902, case I, confirmed later by Fincher and Coon, 1929, and Zülch, 1937), the spinal cord (Saxer, 1902 ; Kernohan, 1932) and the cauda equina (Saxer, 1902 ; Kernohan, 1932). Their ependymal origin is demonstrated for Saxer principally by the cells surrounding the cavities, for Mallory by the blepharoplasts seen in these cells. Saxer already emphasizes the intimate architectural and histogenetic relationship of intraventricular ependymomas with papillomas of choroid plexus, which has been rediscovered more recently.

Thus, at the beginning of this century three main groups of "gliomatous" 
tumours were clearly distinguished : (1) one group characterized by purely expansive growth, lobulated and papillary architecture, arrangement of the ependymalike cells around vessels or cavities, situated in the IVth ventricle or in the brain hemispheres, spinal cord, or cauda equina ; (2) one group of slow clinical course, characterized by a diffuse, unlimited type of growth superimposed on pre-existent tissues and formed by "spider cells" (astrocytes) with glial fibres ; tumours of this type have been seen especially in brain hemispheres and brain stem (pons); (3) one group of macroscopically well-defined neoplasms, somewhat more circumscribed, formed by immature, sarcomalike cells, but connected to group 2 by a similar infiltrative type of growth, and destroying the invaded tissue more rapidly. Nodules of type 3 may occur in cases of type 2, and transitions between both types are encountered.

During the following 20 years the papers are not very numerous, and become already somewhat more interested in the interpretation than in the establishment of facts. Beside the above-mentioned questions of terminology and histogenesis-which only take a small place in the old literature-two main problems are discussed : that of the mode of formation and growth of gliomas and that of their eventual causal relationship with local malformations (heterotopias). Both are problems of general tumour research applied to gliomas. The first problem is, whether gliomas grow aus sich heraus by simple progressive division and migration of the cells which primarily constitute the tumour (Stumpf, 1911; Ranke, 1911; and most other authors) or by progressive transformation of the primarily normal glia surrounding the glioma (Storch, 1899) or whether they constitute primarily diffuse neoplastic glia proliferations (Rindfleisch, 1886 ; Henneberg, 1897 ; Landau, 1910). No clear solution to this question could be reached, except for the rôle played in the formation of gliomas by eventual local disturbances of the brain's evolution during the embryonal period. On the whole, these theoretical considerations never dominate the descriptions. Thus, in 1912, an excellent descriptive and highly comprehensive study was given by Tooth. This is the first glioma study which tries to link the clinical course and the morphological structure of the cases, all previous papers having either neglected the clinical aspects, or described them carefully only in isolated cases (Henneberg, 1897). For the first time Tooth used extensive neurosurgical experiences for the study of gliomas, and drew therapeutical conclusions. Further, it is the first study based on a very large material ; this is especially important : (1) because all previous works concern small numbers of cases; (2) because most subsequent papers, although using even larger series of cases, never give such detailed and objective description as is found in Tooth's paper. Tooth created neither new names nor schemes, and that obviously is the reason why his paper is practically forgotten by all following authors. He first made the important statistical statement that gliomas are by far the most frequent intracranial tumours, forming 127 out of his 258 verified cases (49.2 per cent.). He insisted again upon the slow clinical course of the tumour type known to-day as cerebral " astrocytoma." His case 2 is a typical cerebellar astrocytoma, and he removed it successfully without recurrence. He describes the frequent occurrence of multiple small cysts and rarely of a single 
large cavity in the "benign"; the almost constant presence of extensive necrosis in the " malignant" type of gliomas ; and insisted upon the clinical importance of these degenerative lesions. He was the first to emphasize the importance of curious vascular proliferations in the more malignant, highly cellular types of gliomas and compared them to "glomerular" formations. He emphasized not only the occurrence of quite different histological tumour types in different places of one and the same glioma (a fact already known to Virchow, Stroebe, and Henneberg), but gave to this co-existence a dynamic interpretation : " benign" glioma types may develop into malignant ones. He even supposed " with the greatest possible diffidence" that incomplete extirpation may favour such a malignant transformation because he observed a change of the tissue character in the sense of progressive malignancy by means of subsequent operations. On the whole he considered gliomas, with some exceptions, as inoperable tumours, although incomplete removal is justified by the periods of relief obtained this way.

Tooth's work is one of the most comprehensive papers ever written on gliomas, especially because of his vivid appreciation of the dynamic character of these neoplasms and the very critical use he made of operation specimens.

\section{The Histogenetic Period}

In 1918 Ribbert, whose influence was already responsible for the progressive infiltration of more speculative histogenetic and ætiological discussions into the glioma literature since the heginning of this century, published his paper "On the Spongioblastoma and the Glioma." This paper would not be worth mentioning were it not for the disastrous influence it exercised both on the methods and the ideas dominating the glioma research during the following 20 years. Until then authors considered histogenetic and other theoretical discussions as accessory to the facts described ; Ribbert and his followers group arbitrarily chosen facts around hypothetical systems. His paper gives a rather poor description of schematical drawings of arbitrarily chosen areas, whose position in the tumour he does not indicate (growth zone ? central parts ?). The drawings are of different but otherwise undescribed tumours, and show "epithelial" formations which, in his opinion, proved the origin of gliomas from slumbering embryonal mother cells. The conclusions of his workobtained by merely theoretical deductions - can be summarized as follows : differentiated glia cells can never return to a lower degree of differentiation. Thus, gliomas, glioblastomas, spongioblastomas must be explained by the persistence of embryonal cell elements arrested at different stages of their differentiation. Probably the topography of the "dysontogenetic " disturbance also plays a rôle in the structure formation of the resulting gliomas. The objective reader finds absolutely no facts in this paper that would justify these conclusions. All that can be concluded from Ribbert's illustrations is that some of them probably come from ependymal tumours.

Ribbert's paper opens the period of glioma research characterized by the arbitrary emphasis laid on merely cytological studies, neglecting almost com- 
pletely the numerous other aspects of glioma pathology. The dominating method becomes now the cytological study of a fragment of glioma tissue studied with the implicit supposition that it is in any case representative for the whole tumour, the possibility of cellular and structural variations in different parts of the tumour not being seriously considered. Differences between gliomas which are not of cytological or " histogenetic " nature are inadequately studied and have, in any case, to be subordinated to these sole determining characteristics. This tendency has been strengthened by the contemporary extension of the use of so-called "specific" methods of impregnation for the different subdivisions of glia cells isolated by the Spanish school.

The French school alone resists these histogenetic interpretations. Roussy, Lhermitte, and Cornill gave, in 1924, a very clear histological description which distinguishes (fibrillary) astrocytomas, four subgroups of afibrillar gliomas (round cell, fusiform, polymorphous, and ameboid types), glioblastomas and spongioblastomas, and puts the ependymomas and choroid plexus tumours together in one group separated from the other gliomas. The illustrations of Roussy and Oberling's “Atlas" (1931) are among the best which have been published on the histology of gliomas, especially for didactic and diagnostic purposes. Their description obviously adds no essentially new facts to what was known before, and even constitutes a regression in so far as it considers too exclusively the histological pictures detached from all other characteristics. It is, however, important for two historical reasons : (1) as far as histology is concerned, the authors do not violate the facts in favour of schemes ; (2) they maintain this objective description of facts and reject explicitly (Roussy, 1928 ; Roussy and Oberling, 1931) the histogenetic schemes at a time when the investigators of the whole world were defending them as a sacred dogma.

This attitude, prepared by Ribbert (1918) and Globus and Straus (1925), finds its most dogmatic expression in Bailey and Cushing's work $A$ Classification of the Tumors of the Glioma Group on Histogenetic Basis with Correlated Study of Prognosis (1926) ; its title indicates clearly its tendency. Their work first gives a schematic description * of the histogenesis of the brain and the cell forms encountered in it, followed by a chapter describing the corresponding " histogenetic cellular types" seen in gliomatous tumours. The following chapter contains the classification of gliomas according to the histogenetic cellular types encountered in them. Although the authors admit that a glioma is rarely composed of a single type of cells, they affirm that a classification according to the "predominant" type of cell (Bailey and Bucy, 1930) is possible in most instances. As no exact method of determining the predominant cell in an objective manner is indicated, it seems to correspond to a simple impression. A last chapter dealing with the clinical correlations confirms the old rule that tumours composed of less differentiated cells are more actively growing than those composed of more highly differentiated cells; that almost half of all classified gliomas belong to the latter group and thus, except for an eventual inaccessible position, may be regarded as comparatively benign lesions.

* Bailey's scheme of the normal histogenesis of the brain is far from being generally recognized. Hortega (1932) defends a quite different conception. 
This study was based on 412 verified gliomas, including 167 necropsy specimens. The different histological differential stains used are carefully indicated, but there is no indication allowing a judgment whether the necropsy material has been more completely examined than it is possible for biopsy fragments. Large celloidin sections throughout the whole tumour are mentioned for " several " cases of " spongioblastoma multiforme." In any case, local variations, behaviour of growth zones, and pre-existent tissues are not taken seriously into consideration and the important link between the merely cytological descriptions and the macroscopic appearances is lacking.

Only 254 of these 412 cases could be classified in the following scheme :

\begin{tabular}{|c|c|c|c|c|c|}
\hline & & AVERAGE & & & AVERAGE \\
\hline & NUMBER & DURATION & & NUMBER & DURATION \\
\hline & OF & IN & & OF & IN \\
\hline & CASES. & MONTHS. & & CASES. & MONTHS. \\
\hline Medulloepithelioma. & . & 8 & Neuroblastoma & 2 & 25 \\
\hline Neuroepithelioma & 0 & - & Astroblastoma & 13 & $28 \div$ \\
\hline Medulloblastoma & 29 & 17 & Astrocytoma : & & \\
\hline Pinealoblastoma & 3 & 12 & (a) protoplasmaticum & 52 & $67+$ \\
\hline Pinealoma & . & 19 & (b) fibrillare .. $\ldots$ & 39 & $86 \div$ \\
\hline Ependymoblastoma & . & 10 & Oligodendroglioma & 9 & $66+$ \\
\hline Ependymoma & . & $32+$ & Ganglioneuroma & 0 & - \\
\hline $\begin{array}{l}\text { Spongioblastoma : } \\
\text { (a) multiforme }\end{array}$ & & & burs : 2) & & \\
\hline (a) multiforme & 77 & 12 & & & \\
\hline (b) unipolare & 9 & $46+$ & & & \\
\hline
\end{tabular}

Presented in this way, the classification seems extremely clear and attractive both for didactic purposes and for the surgeon who hopes to obtain from the pathologist exact indications for therapy and prognosis. The pathologist, however, would be a priori sceptical in the presence of such a scheme. He knows too well that the histogenesis of immature tumour cells is always hypothetical ; he knows too that identical histogenesis does not mean identical biological behaviour. To test the real value of this classification let us see now whether the scheme corresponds to facts. To test the value of the methods employed, let us see what are their final results, their influence on contemporary glioma research, and the new facts they really brought forward. Bailey and Cushing's monograph can be appreciated only when considered together with their other publications.

Two groups of the scheme are not represented by any cases.* On the other hand, a high percentage of cases remained unclassified. It is true that this seemed due in many cases to an insufficient amount of tissue being examined; however, in 1933 Bailey still quotes the high number of 67 " unclassifiable and rare types" aside of 378 classified cases. Furthermore, Bailey and Cushing's as well as Globus and Strauss's (1925) previous description of the

* Horrax and Bailey (1925), Globus and Silbert (1931) and others describe pinealomas as histologically well-characterized tumours whose structure seems to repeat the embryonol structure of the pineal gland. The tendency to classify almost all pineal tumours (except teratomas) in this group, once again, does not take the facts into account. Pathologists know that tumours of quite different structures occur in the pineal gland (Berblinger, 1926). One of the cases published by Baggenstoss and Love (1939) resembles closely an ependymoma. On the other hand, one begins to call "pinealomas" certain rare diffuse ependymal tumours of the IIIrd ventricle and its neighbourhood (Ford and Muncie, 1938) in spite of a normal pineal body and only because of apparent histologic resemblances (Mackay, 1939). 
"spongioblastoma multiforme" (a new name for the tumours called previously gliosarcomas) make it obvious that the different tumours united under this name are by no means characterized according to their histogenesis, most of their cells being atypical to such a degree that they have not the slightest resemblance with any mature or immature glia cell of the brain. This has clearly been recognized by Penfield (1931). If the spongioblastoma group corresponds to the old gliosarcoma, the astrocytoma is the classical "glioma" and the ependymoma and ependymoblastoma correspond to the papillary tumours well known since the beginning of this century. No essential new facts have been added, neither clinically nor anatomically, to what was previously known about these groups which form the big majority of all gliomas. Their exclusively histological definition has consigned to oblivion for long years, many of their other morphologic characteristics previously established and which are at least as important as their cytology (Scherer, 1940, $a$ and $b$ ).

What new facts have been discovered ? It has been said by Bailey $(1932, a)$ himself and others that the sole really new fact was the discovery of oligodendrogliomas, and that otherwise the main importance of Bailey and Cushing's monograph was to have stimulated research and interest in gliomas (Greenfield, 1936). Both statements are not entirely justified. Beside oligodendrogliomas Bailey and Cushing have brought to our knowledge two highly important glioma groups not clearly isolated before them. Undoubtedly they stimulated to an extreme degree the interest in glioma research, but unfortunately in a wrong direction. The unfavourable influence their histogenetic doctrine exercised upon research is most clearly visible in Bailey and Cushing's work itself, as may be demonstrated by some examples.

In 1925 these authors published their important work on cerebellar medulloblastomas. Although isolated instances of probably identical tumours had been described a long time before them as sarcomas or neuroblastomas, Bailey and Cushing have the great merit of having made a real morbid entity of this group. This important result was not obtained by the merely cytological study which lead to the conception that these tumours are formed by " medulloblasts" (histogenesis considered as highly hypothetical by Penfield, 1931 ; Cox, 1933 ; Russell, 1939 ; and others) but by a careful objective study of life history, macroscopic appearance, point of origin, growth type and spread, and, finally, architecture and cytology. The result is the following : in children (rarely in adults) there frequently occurs a rapidly growing, soft, reddish-grey, rather well-defined tumour, originating from the roof of the IVth ventricle, filling and dilating its cavity and invading moderately the overlying cerebellar tissue, having sometimes a pronounced tendency for extensive spread throughout the meningeal and subarachnoid space of spinal cord and rarely of brain. These tumours are extremely cellular, their cells generally forming a structureless mass, but sometimes also " rosette-like" formations. The rapidly growing, undifferentiated cells have a very scanty cytoplasm, are round, sometimes contain elongated nuclei containing a dense net of chromatin, and resemble those of a round cell sarcoma. Mitoses are very frequent. A mesenchymal stroma is well developed. Thus a tumour entity is described in a way which permits 
easy recognition, and at the same time the biological and clinical behaviour of these tumours has become understandable. If the authors had continued to study their whole glioma material in this way, the science of gliomas would probably offer to-day a quite clear aspect instead of the disappointing confusion now existing. But Bailey was fascinated by the histogenetic doctrine to such a degree that one year later a whole monograph is based on the fiction that merely cytological or " histogenetic" tumour entities (1) exist and (2) are in themselves morbid entities : the cytology alone determined the place of a glioma in the classification, and this view was justified by the clinical correlation, a different average duration of the life-history corresponding to every one of the histogenetic groups. The result was the creation of cerebral medulloblastomas, of fibrillar and afibrillar astrocytomas without clear-cut distinction of their cerebral or cerebellar location, etc.

Cushing, who had stimulated the elaboration of the classification for clinical purposes, obviously became rapidly aware $(1931,1932,1937)$ that many facts were in contradiction with the doctrinal classification. Thus he created (1931) the group of cerebellar astrocytomas because their pathological and clinical behaviour proved to be absolutely different from the cerebral astrocytomas in spite of an apparently identical histogenesis. The isolation of this new morbid entity (frequently cystic, rather circumscribed, slowly growing, predominantly astrocytic tumours occurring in the vermis or cerebellar hemispheres of children and offering a good opportunity for extirpation without recurrency) is again a result of great and undiscussed * importance. It was again obtained not by the application of the cytological and histogenetic principles, but in spite of them. As a contrast, its subsequent application lead to the unfortunate creation of the group of cerebral medulloblastomas. Regarding this group, Cushing stated later on $(1932,1937)$ that they behave much more like oligodendrogliomas and Bailey (1938) recently admitted that he has become sceptical about these cerebral medulloblastomas, which probably were mistaken oligodendrogliomas. The neuroepithelioma, another doctrinal creation, has been recognized in the meantime as identical with the ependymoma (Kernohan, 1932; Bailey, 1938; Russell, 1939). The existence of a cerebral medulloepithelioma is not less hypothetical (see Russell, 1939). The oligodendrogliomas finally, the real histogenesis of which had been proved by means of successful specific impregnations by Bailey and Bucy (1929), Kwan and Alpers (1931), Hortega (1932), Környey (1937), and others, undoubtedly contain tumours of quite different behaviour : slowly and rapidly growing (Penfield, 1931 ; Cushing, 1937) ; well defined (Bailey and Cushing, 1926; Russell, 1939) and extremely diffuse (Löwenberg and Waggoner, 1939) ; invading extensively the ventricular system (Greenfield and Robertson, 1933), etc.

From these contradictions, Cushing (1937) concludes logically that a merely histogenetic definition causes entirely erroneous conclusions if it does not take into account the different evolutions of the tumours. As the purpose of the

\footnotetext{
* Bergstrand $(1932 b, 1937)$ confirmed the essential facts, but interpretated them as malformations and not as true tumours. This entirely erroneous interpretation has been refuted by Bucy and Gustafson (1939).
} 
new classification was precisely to create histological types making definite prognosis possible, this statement admits courageously the failure of the system. In spite of this, Cushing continued with the tremendous majority of authors to apply this system, with the result that tumours of quite different behaviour remain joined under the same name (cerebral and cerebellar astrocytomas) and vice versa. The fact that many authors felt this obvious incongruity between facts and doctrine is expressed by the innumerable modifications of names, schemes, and classifications which form the predominant object of the glioma literature of the last 15 years. They are summarized and discussed in Henschen's (1934) and Bailey's (1938) scholarly reviews, and one must agree with Bailey (1938) that they certainly have brought no serious progress to knowledge. However, this does not prove that progress is not bitterly needed, but only that the right way has not been recognized. If any further proof were needed, it was furnished by Hortega's great work on gliomas (1932). While Bailey and Cushing and most other " histogenetic" investigators made only an incomplete use of the specific methods of impregnation, they are applied here to the utmost and by the hands of their outstanding master. Hortega's work on gliomas constitutes a masterpiece of cytological tumour research which will not be surpassed for a long time. He joins to his excellent technique an absolutely logical application of the histogenetic principles without transgressing the objective description. The result is a classification of gliomas into iso- and heteromorphous glioblastoma, fibrillar and afibrillar astrocytoma, astroblastoma, oligodendrocytoma, and glioepithelioma. In this application of an exclusively histogenetic classification there is no place for clinical or macroscopic aspects, for differences of localization, etc. : thus the medulloblastoma cerebelli disappears completely and is joined to tumours of similar cytological appearance of the brain, called altogether isomorphous glioblastoma. Hortega's astroblastoma is exclusively characterized by the astroblastic character of its cells, but not-as defined by Bailey (1938) recently in obvious contradiction with his own principles- " by cells forming striking palisades around vessels," that is by an architectural criterion. Thus Hortega's astroblastoma group, according to Bailey (1938), includes many "glioblastomas of rather low malignancy or protoplasmic astrocytomas with a tendency to anaplastic transformation." On the whole, Hortega's work is perhaps the only one which applies the histogenetic principle in a really puritan manner without any inconsequent concession to clinical, biological, pathological, architectural, or other considerations. For that reason it demonstrates in a more peremptory manner than all other publications the fact that this principle in itself is inapplicable for both the pathological and clinical classification of the gliomas.

The struggle between facts and doctrine created numerous compromises, which greatly disturbed the logical unity of the scheme without a satisfactory result. Some of these compromises have already been mentioned. Others concern especially the " spongioblastoma multiforme." For this most frequent and thus most important type of /gliomas Penfield clearly recognized in 1931 that it has to be considered outside of the histogenetic scheme, and that its outstanding histological characteristic is a marked proliferation of blood 
vessels. The statement that this name covered tumours of quite different aspect and also different clinical behaviour (Deery, 1933) leads to histological subdivisions such as protoplasmic, microcellular, fusiform and multiform glioblastomas (Bergstrand, 1932, $a$ and $c$; Gagel, 1938). None of these merely histological distinctions was able to transform these subdivisions into clearly characterized tumour entities, any more than three other cytological subdivisions (diffuse, piloid, gemistocytic) suggested for the " cerebral astrocytoma " (Elvidge, Penfield, and Cone, 1935 ; Alpers and Rowe, 1937). For the astroblastoma the cytological criterion has been more and more supplanted by an architectural one-the perivascular arrangement around vessels with hypertropied walls (Bailey and Bucy, 1930 ; Penfield, 1931). In spite of this compromise, clinically and histologically the astroblastoma remained a questionable and never well-characterized entity. With regard to cerebral astrocytomas, Cushing $(1931,1932)$ recognized that many of his cases classified under this name probably should be classified elsewhere, because they were rapidly growing tumours with numerous mitoses. Bergstrand (1932) and Cooper (1935) stated that in numerous cases the cytological distinction between oligodendrogliomas and astrocytomas becomes impossible. These and other similar statements lead to the creation of "transitional forms" expressed in names such as "astroglioblastoma" (Kino, 1935) and others (Levin, 1939). Bergstrand deserves much credit in having emphasized already in 1932 the great frequency of histological transitions between the different cytological " entities." The term "polar spongioblastoma" obviously changes its significance from one author to the other ; Bergstrand (1932), Cox (1934) and Russell and Bland (1934) identify it with Penfield's " piloid astrocytoma " (fibrillary astrocytoma distinguished by elongated cell forms and polar arrangement of its fibres instead of intertwining network); Hortega (1932) and Roussy and Oberling (1931) seem to identify it with certain oligodendrogliomas. The tendency to call more and more gliomas in the brain stem "polar spongioblastoma" (see Echols, 1938 , and others) is probably explained by the fact that tumour cells of quite different character adapt their shape to the direction of the pre-existing nerve fibres, the "polar" arrangement of which is more pronounced in the brain stem than elsewhere. The very incomplete description of most of the published cases allows no judgment about their real character. Authors with still more imagination consider the elongated form of cells as sufficient to justify the description of a "central diffuse Schwannosis" (Foerster and Gagel, 1934 ; Santha, 1936).

More clinical points of view together with the unsatisfactory results of merely histological researches provoked a considerable number of papers which analysed tumours of a determined localization, such as gliomas of the pons (Buckley, 1930 ; Alpers and Yaskin, 1939 ; and others), of the thalamus (Smyth and Stern, 1938), mesencephalic gliomas (Alpers and Watts, 1935), etc. These papers either deal with tumours of different histological structure in a given localization or bear histological names such as "astrocytomas of oblongata, pons, and midbrain " (Foerster and Gagel, 1939, and others). In the first case, authors often try to force tumours into a given localization: thus Buckley 
mentions that in many of his pontine gliomas the cerebellum was much more involved than the pons! In the latter case the tendency is again to force tumours into the histological diagnosis given in the title. Case 6 of Foerster and Gagel's astrocytomas is obviously a glioblastoma. These examples show that the tendency, characteristic of the whole histogenetic period, to schematize facts, has unfavourably influenced these otherwise very worthwhile papers. Therefore the conclusions and the statistics based on them have to be accepted with the greatest reserve. It is significant that Smyth and Stern (1938), who examined their cases very completely, renounced immediately schematic histogenetic diagnoses of most of the described cases. Even the use of the method of tissue culture has been subordinated to the histogenetic ideology (Kredel, 1928 ; Buckley, 1929 ; Buckley and Eisenhardt, 1929 ; Russell and Bland, 1933, 1934 ; and Cox, 1937). It generally leads to the somewhat sterile conclusion that the cells grown in the cultures resembled those seen in the microscopic sections of the glioma from which the cultures were taken. Only Russell and Bland (1934) made an important statement : cells from a histologically typical " polar spongioblastoma" formed typical astrocytes in the cultures. They draw the conclusion that Bailey's polar spongioblastoma is in reality a piloid astrocytoma (Penfield).

Schwartz $(1932,1936)$ and later Ostertag $(1934,1936)$ tried to replace the histogenetic classifications by the elaboration of localization types of gliomas, in the same manner as the localization types of meningiomas elaborated by Cushing. The existence of these types, repeated with constancy, seems to be clearly established by Schwartz's paper and corresponds perfectly to the writer's personal experience. But before sufficiently definite results could be obtained by Schwartz, Ostertag abandoned the objectively descriptive method by mixing those localization types with hypothetical interpretations which created new confusion. In any case, a pure study of the localization of gliomas is certainly no more justified than a purely histological study.

One may summarize the general results of the histogenetic period of glioma research as follows : two important glioma entities have been brought to our knowledge - the medulloblastoma by Bailey and Cushing (1925) and the cerebellar astrocytoma by Cushing (1931)-both discovered independently of the histogenetic principle. To this principle is due only the isolation of oligodendrogliomas by Bailey and Bucy (1929) ; these tumours form probably a histogenetic but certainly not a morbid entity. The consequent application of the histogenetic principle is not justified by clinical correlations as recognized by Cushing himself. It has created tremendous confusion as far as the pathology of gliomas is concerned, and provoked an enormous amount of work devoted to a forlorn hope. Innumerable histological details have been carefully described, but generally they are detached from the general pathology of the concerned neoplasms. They provoke arbitrary interpretations and cannot be used for the creation of a pathology of gliomas. 


\section{The Period of Complete Glioma Examination and Its First Results}

Confronted with this disappointing situation and with an already extensive personal experience with gliomas, Scherer (1935a) came to the conclusion that the histogenetic principle as a basis of glioma research and classification could not be improved, but had to be given up for numerous reasons of technique and principle. Many errors of the histogenetic period of glioma research are caused by the blind faith of the authors in modern " specific" staining methods. It is obvious that there are no methods which are entirely specific in every circumstance, and thus that they have to be used with great reserve. This is especially true when methods worked out for normal brain tissue are applied to tissues the physico-chemical conditions of which are deeply modified ; this is undoubtedly the case in many brain tumours (Singer and Seiler, 1933). Furthermore, if these methods worked out for normal cell elements may give useful results for mature tumours, they cannot be expected to determine with certitude the nature of immature or anaplastic tumour cells. Based on the critical analysis of two cases of " glioblastoma multiforme ganglioides" (Foerster and Gagel, 1931) and of many ganglioneuromas* in the literature, Scherer's paper (1935b) gives ample proof that the use of specific stains in brain tumours of low differentiation does not lead to certitude, but to entirely arbitrary interpretations of their histogensis. Recently, Bailey (1938) admitted explicitly that he was previously " overly impressed with the specificity of silver methods." The best illustration of this fact is furnished by the frequent change of the classification of one and the same tumour encountered in the different papers of Bailey (1938) and Cushing (1932). The specific methods, although valuable auxiliaries for the solution of determined questions of detail (see Bailey's discovery of oligodendrogliomas), cause many more errors than progress when taken as a general technical basis of glioma research. Thus, a technical insufficiency already renders a histogenetic classification of immature gliomas impracticable.

Not only specific stains but also the possibilities of merely histological methods in general have been extremely over-estimated by authors who, although sometimes excellent histologists, were no pathologists. Histology is one of the methods of pathology; it is not pathology. The fact of not reckoning with this fundamental principle-perfectly applied from Virchow until Ribbert-is undoubtedly much more responsible for the disappointing stage of modern glioma research than is the uncritical use of specific stains. The contemporary progress of neuro-surgery greatly favoured these tendencies. The study of biopsy material may be a practical necessity for neurosurgery; it never can be in itself an adequate method for pathological tumour research. Most modern investigators consider the use of small fragments as the normal method for glioma research to such a degree that they obviously examine even their necropsy material in the same incomplete way. This attitude explains why most modern papers do not even indicate whether necropsy or biopsy material has been studied, and why the authors use both mixed together, without indicating the proportion nor separating the conclusions drawn from both kinds of cases.

* In spite of this work, those cases continue to be quoted as "ganglion cell tumours" (Wolf and Morton, 1937). 
The importance of this fact can hardly be overstressed ; Bailey and Cushing's classical description of the medulloblastoma group was obtained from a large amount of necropsy material, while their relatively poor and inadequate description of cerebral astrocytomas is obviously due to the extreme scarcity of necropsies. The rare glioma papers of the histogenetic period which studied necropsy material carefully (Carmichael, 1928 ; Davidoff and Ferraro, 1929 ; Cox, 1933 ; Deery, 1933) immediately stated facts which should have prevented a continuous use of biopsy material. Technique and ideas can never be separated from each other. The main problem of gliomas as well as of all other neoplasms is a growth and not a differentiation problem. As a glioma is not a dead phenomenon but an eminently living one, a dynamic point of view must try to study in the first place evolutionary stages and growth processes. A tumour is not a heap of cells independent from the tissue in which it grows. It only can be understood when studied in all its parts, especially in its growth zone and in its natural relationship with the tissue from which it originates. No specific staining of glioma fragments and no oil immersion can replace the complete study of the whole brain (Scherer, 1935a).

These considerations lead the author to the exclusive use of necropsy material for his glioma investigations and to the application of the following technique * of " complete" study of gliomas (Scherer, 1935a, 1938b, 1939b) :

After the whole brain has been fixed in formalin, it is cut into $15-\mathrm{mm}$. thick frontal slices. The slices showing a macroscopical modification are photographed. All slices containing the tumour from its frontal to its occipital end, with a large amount of surrounding macroscopically unchanged tissue, are imbedded in celloidin. As glioma growth very!frequently is much more extensive than supposed from the macroscopic aspect (Scherer, 1939a; 1940a), one has to study as many normal parts of the brain as possible. One, or sometimes several, thin but also very large slices are sacrificed for frozen and later on for paraffin sections, stained and impregnated by the different selective stains used in modern neuropathology. The celloidin blocks are cut quite deeply from both sides in order to obtain a kind of incomplete serial section study of the whole tumour and surrounding tissues. The ideal method, a real serial section study, is impracticable with a large material. The celloidin sections are always cut at $20 \mu$ in order to allow objective comparisons of cellularity, and stained with the Nissl, Van Gieson, and partially the Achucarro methods. A glioma being a cellular overgrowth, the necessity of a nuclear stain as a fundamental method must be emphasized ; large Weigert stained sections such as have been used recently by Waggoner and Löwenberg $(1937,1939)$ may give misleading results, even when completed by nuclear stains of some smaller fragments. To obtain the important link between macroscopic and microscopic pictures the Nissl stained sections are photographed in natural size, and the

* The great importance of both a really " complete" study and a very large material is illustrated by the fact that Kino (1935), who also tried to complete the merely cytological researches by a study of growth character, etc., reached no clear results : his technique was not complete enough and his material too small. Deery (1932) and Elsberg and Hare (1932) also felt the need of more complete techniques, but they also did not go far enough, and they applied their method to more limited questions. 
extension of the tumour demonstrated in this way is carefully compared with the macrophotographs of the formalin-fixed brain slices. Then a careful microscopical study of all parts of the tumour is made; numerous photomicrographs are taken in order to allow objective control. The results are recorded in the following scheme : age, sex, duration of clinical symptoms, clinical diagnosis, brain's weight, presence or absence of brain swelling, exact localization, macroscopic aspects, mode of growth and extension, cytology, cellularity (determined by systematic counting: Scherer, 1940b), structural behaviour (Scherer, 1938b), behaviour of pre-existent tissues, mesenchymal structures, regressive changes, reactive changes, inflammation, particularities.

In that way, all the morphologic properties of a glioma are objectively recorded ; to characterize the tumour, none of them is given more weight than another. The principle of the author's glioma research (Scherer, 1939b) is that of all descriptive natural sciences. A glioma is a natural phenomenon. A natural phenomenon is characterized by the whole of its morphological and biological characteristics ; it would be easy, but arbitrary, to classify an animal according to the number of its teeth alone or a plant according to the form of its leaves only. It is not less arbitrary to subordinate study and classification of gliomas only to their cytology or to their localization. It is fantastic to base a classification not on observed facts but on interpretations (histogenesis instead of cytology, embryonal ætiology instead of localization : Ostertag, 1936).

The thorough application of this method of complete glioma examination takes a considerable time because of the large surfaces and great number of sections which must be studied in every case. This probably explains why it has not been applied until now by others, all the more as only the study of numerous cases could prove whether this tedious method would finally give worthwhile results or not. After the study of 130 cases during 8 years, the value of the method not only for pathological but even for clinical problems became obvious. This method will necessarily lead to a natural classification of gliomas deduced from facts instead of theoretical classifications imposed on facts, but not before several more hundreds of cases have been studied. As the natural classifications of all natural phenomena, that of gliomas certainly needs the collaboration of a large number of individuals using exactly the same methods of studying and recording, and this during long years. No new terminology will be proposed until this natural classification has been steadily established. As the only important principle of terminology is to avoid suggesting interpretations not supported by facts (see Ewing, 1936), the best would be a simple lettering and numbering of groups and subgroups $(\mathrm{A} 1,2,3$; B1, 2, 3). Meanwhile the generally adopted names will still be used with the clear understanding that they have no " histogenetic" significance. A striking example will show how the definition of the future natural groups will differ from the actual cytological definitions : the only diagnostic criterion of the cerebral astrocytoma of the cytologists is that it must be situated in the brain and composed predominantly by astrocytes. Scherer $(1940 b)$ quotes the extremely contradictory indications resulting from this definition in the modern literature about astrocytomas, and comes to the following definition : the tumours commonly called 
cerebral astrocytomas are characterized by their diffuse character of growth, their generally enormous size, their moderate and uniform cellularity (except very old cases which may reach a considerable cellularity), the uniformly "amorphous" structure, the astrocytic character of a high but variable percentage of their cell elements, the histogenesis of a considerable percentage of which is doubtful ; the production of glial fibres in small or extensive areas ; the preservation of the pre-existent nervous parenchyma (nerve cells and fibres) in the tumour ; the tendency to microcystic degeneration of a type specific for astrocytomas ; the absence of necrosis ; the low vascularity without endothelial or adventitial proliferations ; the slow clinical course.

Let us now resume the preliminary theoretical and practical results obtained until now. A first series of systematic researches (Scherer, $1936 a, b ; 1937$; $1938 b$ ) dealt with the finer proceedings displaying themselves in the growth zone of gliomas and their relationship with the pre-existent structures of the nervous system. Their study has been completely neglected by the modern glioma research, and the older papers had studied them in isolated cases only. It could be demonstrated that not only the spread but also the architectural development of gliomas is influenced to a high degree by the pre-existent tissue. Thus, a striking arrest of the growth of white matter gliomas at the grey matter (cortex, striatum) is very frequent, and certainly cannot be explained by mechanical factors (Scherer, 1936a). It creates the digitiform outline of many gliomas. Much rarer is the opposite, a systematical intracortical form of growth without invasion of the white matter. Nerve cells and fibres (Scherer, $1936 b, c)$ play a prominent rôle in growth and structure formation of very numerous gliomas of quite different histology : frequently one observes that, as a glioma begins to invade the cortex or other masses of grey substance, the first manifestation of the neoplastic process is a collection of glioma cells around all or a great number of the nerve cells ; this perineuronal growth may occur in a precocious form (in a cortex otherwise relatively free from tumour cells) or as late phenomenon (in a cortex already heavily infiltrated by the tumour). After the disappearance of the nerve cells, these groups of tumour cells may persist and imitate the normal architectural pattern of the invaded region in a striking way. Extensive perivascular growth outside the Virchow-Robin spaces (Scherer, 1937) is also extremely frequent, and may, in rare instances, dominate the whole architecture of a glioma (Scherer and De Busscher, 1937). All these glioma structures conditioned by the pre-existent tissue are called " secondary structures" (Scherer, 1936b; 1938b). They are infinitely more frequent and more important for the architecture of gliomas in general than the " proper structures," which are architectural patterns independent from the invaded tissue and thus probably conditioned by the intrinsic architectural properties of the neoplastic tissue. " Proper structures" dominate exclusively the architecture of ependymomas, which show a purely expansive type of growth. The structural behaviour varies greatly from one glioma to the other and in different stages of the growth of one and the same case (Scherer, 1938b). Thus, certain gliomas show always an " amorphous" (structureless) arrangement of their cells, although nerve cells and fibres are perfectly preserved in the midst of 
the tumour. This behaviour is encountered, for instance, in all typical cerebral astrocytomas ; the same tumours may show extensive evolution of secondary structures when dedifferentiation into " glioblastoma " occurs in them (Scherer, $1940 b$ ). Other more frequent gliomas are characterized by a primary growth in the form of secondary structures, followed by an " amorphous " stage and finally by various "proper structures." The characteristic differences of the structural development in gliomas can only be considered as an expression of fundamental biological differences of the tumours themselves, and thus are an important morphological characteristic of them.

These findings raise important questions of pathogenesis : are the curious secondary structures due to a progressive neoplastic transformation of the pre-existing glia cells (for instance, the satellites of nerve cells, the perivascular glia cells), or to a selective migration of glioma cells towards these pre-existing structures? The first interpretation corresponds best to the facts observed and has thus been repeatedly defended since Storch (1899); but it is in opposition with a still dominant fundamental dogma on the growth of neoplasms. The second interpretation would put the problem of the causes of this curious " neuronotropism" of glioma cells. It certainly cannot be interpreted-as could perhaps be the perivascular growth-by nutritional necessities. Obviously those problems cannot be solved by morphologic methods alone; but they should be attacked with the help of the new methods allowing an experimental glioma research (tissue culture, experimental gliomas by carcinogenetic agents).

Another question of pathogenesis (Rindfleisch, 1886 ; Henneberg, 1897 ; and Landau, 1910) seems to be resolved already by morphological methods : namely that of the primary diffuse growth character of certain not infrequent brain tumours, especially of so-called cerebral astrocytomas. Scherer (1940b) applied his method of "complete" glioma examination to this group with the following result : the tumours commonly called cerebral astrocytomas are always primarily diffuse gliomatous overgrowths, comparable to lymphosarcomatosis. This fact has been proved by the observation of astrocytomas from patients who died accidentally at a time when they were just beginning to give rise to symptoms, which already showed entirely diffuse neoplastic overgrowth of uniformly low cellularity in all its parts. One never finds in astrocytomas systematized differences of cellularity which would suggest that "the growth starts in an area which is the nucleus of the tumour," as supposed by Waggoner and Löwenberg (1937). Furthermore, Scherer confirms for astrocytomas an old suggestion made by Golgi $(1875,1884)$ : the cortical parts of these diffuse tumours are afibrillar (except the subpial layer), even when their white matter parts are highly fibrillary. That corresponds exactly to the local differences presented by the normal astrocytes and those found in reactive proliferations. This behaviour cannot be explained by tumour cells coming from the white and invading the grey matter or vice versa, but only by neoplastic proliferation of the local elements which maintain their fibrillar or afibrillar character.

But the method of complete glioma examination already has given results of 
practical interest. The cerebral astrocytomas such as were studied during the histogenetic period were one of the groups which had given rise to most contradictory opinions on questions of great practical importance : their frequence, their diffuse or circumscribed character, their ability for anaplastic degeneration and the eventual causal relationship of this degeneration with surgical interventions (Tooth, 1912 ; Globus, 1931 ; Müller, 1933 ; Scheinker, 1938a) are only some much discussed points, a clear answer to which must have therapeutic consequences. Scherer $(1940 \mathrm{~b})$ stated the following facts : of 125 gliomas, only five "pure" cerebral astrocytomas have been encountered; 13 other cases of this group include microscopically (four cases) or macroscopically visible areas of glioblastoma. Their whole morphology and the clinical aspect prove that these are astrocytoma derivatives. Not a single circumscribed cerebral astrocytoma has been found : all were primarily diffuse growths of generally enormous size. There are cerebral astrocytomas which show no dedifferentiation into glioblastoma at necropsy, even after a duration of 10 years, in spite of operations performed many years before death; the majority shows such a dedifferentiation without any operation. This is a striking proof that the surgeon is not responsible for this "malignant degeneration," contrary to some opposite opinions defended previously after the usual study of fragments of tissue. Those " secondary " glioblastomas have to be strictly separated from the " primary" ones; the most striking difference on necropsy material is that the former show no or comparatively small necrosis (not over about $\frac{1}{10}$ of the living tumour tissue), while in the latter the necrotic areas are almost always more extensive than the living tumour tissue. Small cystic degeneration of the type encountered in astrocytomas is not found in primary glioblastomas. Once more facts prove the error of an abstract doctrine, namely that degenerative lesions have no importance for the classification of tumours (Bucy and Gustafson, 1939). The clear separation of primary and secondary glioblastomas renders also the clinical and biological differences much clearer : the cases of "glioblastomas with long clinical evolution" quite probably are a result of incompletely examined astrocytoma derivatives. The evolution of none of Scherer's (1940b) primary glioblastomas reached one year, in most cases it was beyond 6 months.

The new definition of cerebral astrocytomas as primarily diffuse growths join them into one group with the numerous isolated cases published under such names such as "gliomatosis cerebri" by Landau (1910), Angyan (1912), Bielschowsky (1915), Cassirer and Lewy (1923), Schwartz and Klauer (1927), Foerster and Gagel (1934), Santha (1936), and most completely studied by Nevin $(1938 a, b)$. These cases have all the growth characteristics of the classical cerebral astrocytomas, such as have been elaborated since Virchow, and also their clinical behaviour ; most authors did not dare to classify them because of the existence of numerous non-astrocytic elements. The excellent objective description of Nevin makes it unquestionable that these are dedifferentiated diffuse astrocytomas.

For the primary glioblastomas the complete examination shows at least two, probably more, definitely distinct pathological (not histological) entities. The 
exact limitation of these groups and their eventual clinical correlation needs still further study.

In another systematic study devoted to a problem of practical interest, Scherer (1938c) studied the frequency of gliomas having variable histological structure. Almost all authors of the histogenetic period consider implicitly or explicitly the uniform structure of gliomas as established to such a degree that their whole method-that of the study of arbitrarily taken fragments of tumour tissue-is based upon this doctrine. Only some more careful modern workers (Carmichael, 1928 ; Davidoff and Ferraro, 1929 ; Cox, 1933 ; Deery, 1933) had stated with necropsy material that mixtures of different cytological glioma "entities" in one and the same case are not infrequent and must cause errors when examined as operation material. Thus they confirm what already Virchow (1863-1865), and after him many others, had seen. However, the practical importance of those combinations depends obviously on their frequence, and this could only be determined by "complete" examinations : these proved that definite mixtures of recognized cytological entities occur in about 40 per cent. of all gliomas, and that in about 26 per cent. "benign" and "malignant" types are mixed. This frequence has been contested by authors who have not applied the method of "complete" glioma study ; as the percentages discovered exclusively depend upon the quantity of tumour tissue examined, Scherer's percentages can only be contested by an equally complete study of equal numbers of cases. The sole histogenetic "entity" which I have never seen with any mixture is the medulloblastoma. It becomes obvious from these statements that conclusions drawn from biopsy material should be considered with the greatest possible diffidence.

Finally, the growth forms of gliomas have been systematically studied from a practical point of view (Scherer, 1939a, 1940a). For all tumours, the anatomical features most important for the clinician and surgeon are localization and growth type. They have a direct and decisive influence on the possibility of complete extirpation. The cellular aspect of a neoplasm can only give indirect indications, and that only if its constant correlation with a given type of growth is well established, e.g. for carcinomas. The pathology of gliomas, however, is still far from this stage. The growth type of gliomas has received so little attention in modern papers that even the words "growth zone" are entirely lacking in most of them. In view of the neurosurgical purposes of most of these papers, this omission is astonishing. The sole connected problem carefully studied is that of glioma metastases in the ventricular system (Russell and Cairns, 1930 ; Cairns and Russell, 1931 ; Bodechtel and Schüler, 1937 ; Hasenjäger, 1938) with the result that those metastases are not specific to medulloblastomas, but rarely may occur also in almost every type of glioma. Nelson (1936) even described a small intravertebral metastasis of a medulloblastoma. As the previous communications (e.g. Mittelbach, 1934) on gliomas with metastases outside the nervous system are more than questionable, Nelson's case would be the first authentic instance of such a metastasis.

Scherer's statements may be resumed as follows : only one rare type of 
glioma, the ependymoma, shows the purely expansive growth which alone gives good chance for extirpation without recurrence. All the others are infiltrative without exception, and thus realize the essential morphological criterion of malignancy (Ewing, 1928). However, in many cases (about 30 per cent. of all gliomas, including cerebellar astrocytomas, medulloblastomas, certain oligodendrogliomas, many glioblastomas) the zone of growth is so narrow that it coincides approximatively with the macroscopical visible limits and thus may give a chance for complete removal, all the more as secondary factors (arrest of the tumour at the cortex, etc., marginal degenerative lesions) may strengthen the circumscribed character. But the majority of gliomas is much more extensive than the macroscopical aspect leads us to suppose : about 60 per cent. have a more diffuse character with a widespread zone of growth, the diffuse nature being either secondary (about 35 per cent.) or primary (about 25 per cent., including all astrocytomas of brain hemispheres and brain stem). About 10 per cent. of all gliomas-most of them belonging to the glioblastoma groupare primary multicentric growths, half of which are macroscopically visible as multiple tumours. This fits in fairly well with the percentage of multiple gliomas obtained by Courville (1936), while incomplete study may give either too low (Bailey and Cushing : 2 on 412) or too high percentages (Globus and Strauss, 1925 ; 6 on 17 ; Brandt, 1934: 4 on 20 cases), the latter probably because the unique character of a glioma with digitiform shape had not always been recognized. On the whole, identical "histogenetic" groups include gliomas of quite opposite behaviour of growth. The most "mature " types (cerebral and pontine astrocytomas) are the most infiltrative and thus the harder to extirpate completely.

Infiltrative and destructive growth are by no means synonymous in gliomas and this is of clinical importance. A long preservation of nerve cells and nerve fibres in the midst of the tumour is not specific to astrocytomas, but is also encountered in a lesser degree in many glioblastomas. The ignorance of this fact known in principle since 1895 (Stroebe) and the subsequent erroneous interpretation of these pre-existent nerve cells as tumour cells is one of the obvious reasons why certain authors find so many " gangliogliomas," "glioneuromas," etc. (Globus, 1938), while others have not seen them at all or quite exceptionally. The other is the too generous application of the term " neuroblast" to cells whose neuroblastic character is at least unproven. The writer entirely confirms Cox's statement that the neuroblast is particularly difficult to identify. Cox also gives a very comprehensive study on the rôle of pre-existent glia cells included by the glioma.

On the whole, the extensive use of the method of "complete" glioma examination seems to be justified by the first results obtained, especially if one considers that we are only at the beginning of these researches. Their purpose is to replace merely academic investigations on cytologic questions by a living pathology equally useful to both clinician and pathologist. In many respects, they take up again the study of gliomas where it stood before the histogenetic period, but in a more systematic way : a much larger material than in the classical researches is studied with a much more complete method, and the 
enormous progress made during the last 30 years by both neuropathology and cancer research are applied to the pathology of gliomas.

\section{Some Particular Aspects of Glioma Pathology}

There remains a certain number of particular aspects of glioma pathology not yet discussed in this review. We will not go here into details about the lesions occurring in glioma brains outside of the tumour. They consist in hæmorrhages or necroses, brain swelling or brain œdema, and in cysts. Hæmorrhages in the brain stem are frequent in brain tumours of quite different location : Rosenhagen (1932) observed them in 10 out of 16 cases. Bannwarth (1935) had the impression that temporal tumours produce these lesions more frequently than others. Moore and Stern (1938) emphasized the occurrence of hæmorrhagic infarction of the visual cortex alone or together with hæmorrhages in the brain stem. Bodechtel and Döring (1938) observed also softenings in other locations (basal ganglia, diencephalon, etc.). While Moore and Stern believed that surgical procedures have no pathogenetic significance, Kaufmann (1938) defends the opposite opinion. All authors agree that these lesions must be considered as consequences of the increased intracranial pressure and its effects on the cerebral circulation. Less clear is the pathogenetic relation between brain swelling and glioma. While the histology of brain œdema has recently been studied by Greenfield (1939), the ætiology of this important phenomenon has given rise to numerous hypotheses but to few really established facts. Extra-neoplastic cysts in the surrounding brain tissue have been described for cerebellar astrocytomas (Bucy and Gustafson, 1939).

The literature contains innumerable indications, but no systematic studies on degenerative lesions in gliomas. They cannot be discussed in this paper. It may be presumed that large cysts are frequent in cerebellar, but relatively rare in cerebral astrocytomas and ependymomas. Extensive necroses are specially characteristic of primary glioblastomas, but occur also in ependymomas, although never in pure cerebral astrocytomas. Further studies unhampered by histogenetic tradition are certainly needed.

Two other questions have still to be discussed because of their interest for general pathology. One concerns the occurrence and significance of mesenchymal stroma and vascular proliferations in gliomas. There are definite differences of vascularity in different types of gliomas, but beside the careful work of Elsberg and Hare (1932), few systematic studies have been devoted to this question. Recently the benzidine stain has been applied with some success to this problem (Sahs and Alexander, 1939 ; Bertha, 1939). It shows that the degree of vascularity is not proportional to the rapidity of growth : while "astrocytomas" have a very low vascularity, the usually slowly growing " oligodendrogliomas" are extremely rich in capillaries. However, more extensive studies unimpeded by the histogenetic schemes are greatly needed. Those who recorded objectively the facts were always impressed by the importance of mesenchymal and vascular proliferations especially encountered in so-called glioblastomas (Tooth, 1912 ; Bertrand and Medakowitch, 1922 ; 
Penfield, 1931 ; Scherer, 1933, 1935c ; Torkildsen, 1935 ; Bertha, 1939) and emphasized their important rôle for the whole of the morphologic characteristics of these tumours. The special angioplastic proliferations, contrary to Bailey and Cushing (1925), Deery (1932), and others, cannot be considered as banal, reactive vessel proliferations, at least not their glomerular type (Scherer, 1935c): they are not seen outside of these gliomas. Penfield's (1931) opinion that they are the essential histological characteristic of glioblastoma multiforme does not correspond entirely to facts, in so far as these formations rarely may appear also in other types, especially in astrocytomas, together with dedifferentiation -(Scherer, 1940b). In very pronounced form these angioplastic proliferations have always been observed in cases with extremely rapid evolution (Scherer, 1935c). This and the curious fact that they precede the growth of the tumour, growing from the uninvaded tissue towards its edge (Scherer), give to them a biological significance which has not been clarified until now. In spite of the numerous mitoses found in these proliferations, it is neither proved nor excluded that they are a real part of the neoplastic growth process (" angiogliomas," Roussy and Oberling, Holtzer, 1939). They too certainly deserve further careful research.

Still less solved is the important problem of combined cases of glioma and mesenchymal sarcoma, as far as it is not interpreted as a simple coincidence, but either as primary combination or as " reactive glioma" around a primary sarcoma. These cases have been described by Merzbacher and Uyeda (1910), Wohlwill (1911), Cornil and Robin (1922), Pines (1922), Neubürger and Singer (1926), Gulotta (1933), Bailey and Ley (1934), Marburg (1935), Spatz (1938). Most authors consider their cases as primary meningeal sarcoma with secondary glioma, while Bailey and Ley defend the opposite opinion for their case. The writer examined three (unpublished) cases of this kind and had also the impression that the gliomatous tumours probably were secondary to the meningeal neoplasms. This question has a great theoretical importance : the proof of a causal dependence of the gliomatosis upon the meningeal tumour would mean that the latter provoked the former by "induction." The importance of this question, the doubtful character of some of the published cases, and the enormous difficulty of correct interpretation of such tumour combinations (see Saphir and Vass, 1938) should impose the greatest possible caution before definite conclusions are drawn from these curious cases.

\section{Atiological Problems. Experimental Glioma Research. Comparative Pathology of Gliomas}

The same reserve, always necessary when ætiologic conclusions have to be reached by morphological methods, is necessary in the rare but important cases of combination between true glial neoplasms and lesions belonging to the group of multiple and diffuse sclerosis or " disseminated encephalomyelitis." In some cases of acute " multiple sclerosis" highly atypical glial cells of neoplastic appearance have been observed (Creutzfeld, 1923 ; Peters, 1935 ; and others), and Hallervorden (1930) describes several cases where the definite differential 
diagnosis between a glioblastoma and an acute multiple sclerosis was not possible. Scherer (1938a) described a case where a typical disseminated encephalomyelitis and multiple tumours of the type of "glioblastoma multiforme " were combined in such a way that the direct evolution of the neoplasm from the encephalitis was very probable. Schöpe $(1938,1939)$ published two similar cases, but interpreted them in a way (Hodgkin's disease of the brain without manifestation in other organs !) which was quite unsüpported by the facts described. The writer had the opportunity of studying sections of Schöpe's first case and must state that it certainly has nothing to do with Hodgkin's disease, but belongs clearly to the group of cases here discussed. Their great importance is that they suggest the possible rôle of extrinsic ætiologic factors for the ætiology of gliomas. It must be mentioned in this connection that Russell (1932) described curious " intranuclear inclusion bodies" as very frequent in glioblastomas and insists upon their resemblance with such inclusion bodies described in virus diseases.

This has to be emphasized because until now almost exclusively intrinsic factors, or, more precisely, an ætiology by displaced embryonal cell nests, have been taken in consideration. It would be difficult to find a more striking example of doctrines influencing the judgment of investigators to such an extent that they take for granted a hypothesis unsupported by seriously established facts. Since the last century authors always discussed this hypothesis under the influence of Cohnheim and Ribbert's theory relating all neoplasms to such slumbering embryonal mother cells. The fact that certain gliomas rise in brains with tuberous sclerosis (Bielschowsky, 1924 ; Globus, Strauss and Selinsky, 1932) proves nothing for the enormous majority of gliomas where the slightest sign of tuberous sclerosis cannot be found : the author has not encountered one single case of this coexistence in 130 gliomas the brains of which were completely examined.

As mentioned above, Ribbert (1918) first presented this hypothesis as a wellestablished fact for all gliomas, but without any proof. Since that time many authors consider this theory as sufficiently established for building their whole system upon it, while others state that " the evidence is practically conclusive that these tumours (i.e. gliosarcomas) arise from once adult cells, and that their structure and behaviour are determined by anaplasia and not by embryonal qualities" (Ewing, 1936). Ostertag still tries, in 1936, to accredit the "dysontogenetic" hypothesis not only for some but for all gliomas, to "explain" in this way not only their ætiology but even their whole histology, localization, and biological behaviour, and calls the desultory and illogical result a " natural classification explaining location, extension, and structure." Ostertag simply repeats the facts already discussed last century (see Stroebe, 1895; Saxer, 1902 , and many others), and adds the supposition that the identical localization, repeated with astonishing constancy by numerous gliomas, corresponds to areas which are predestined, by the embryonal development of the nervous system, to local malformations. If this may be true for some cases, such as medulloblastomas, the enormous majority, by their great extension, does not allow recognition of the point of origin. It is therefore impossible to compare 
its location with that of the incriminated embryonal disturbance. Even if such a local congruity could be demonstrated, it would be no proof for the causal relationship between developmental troubles and glioma growth, no more than the well-known predominant localization of the patches of multiple sclerosis in the periventricular zones proves for such an embryonal relation. Somewhat more interesting would be the evidence of local malformations in given cases of gliomas, but Ostertag describes not one similar case. His interpretation of the frequently very pronounced overgrowth of mesenchymal tissue in gliomas as "primarily abnormal mesenchymation" of the area concerned is not supported by facts (Scherer, 1933, 1935c). The frequently encountered opinion that diffuse gliomatoses ought to be considered as "dysontogenetic" disturbances (Hallervorden, 1936) is not supported by any facts. An extrinsic factor able to stimulate neoplastic growth of a circumscribed area cannot be considered a priori as being unable to have the same effect in a large area. On the whole, Ostertag brings not a single new fact supporting seriously the old hypothesis which becomes a real anachronism in a period where the enormous rôle played by extrinsic factors (carcinogenic agents, viruses) in the ætiology of neoplasms has been proved in a peremptory manner. There is no reason for considering the ætiology of gliomas outside of that of other neoplasms : "Tumours are highly conditioned diseases dependent upon a concatenation of factors-heredity, age, chemical irritation, etc., etc.," says Rous (1936). This should always be borne in mind, also for the much discussed but unsolved question of the "traumatic origin" of gliomas, defended by some (Beneke, 1932 ; Marburg, 1934, and others) and refuted by others (Fischer-Wasels, 1932) with the same emphasis ; for the " hereditary brain tumours" such as described by Hallervorden (1936) and others ; familial occurrence of gliomas, as of all neoplasms, does not prove more for their predominantly hereditary character than familial occurrence of tuberculosis (Rous, 1936).

After all the fanciful ætiological considerations filling the glioma literature until the last years, two recent important advances begin to put facts in the place of hypotheses : the appearance of the comparative pathology of gliomas, and that of experimentally produced gliomas. The first shows clearly that gliomas are relatively frequent in certain animals, extremely rare in others. The frequence of gliomas in the dog has been established especially by Hjärre $(1924,1926)$ and by Milks and Olafson (1936). The latter find primary brain tumours in 4 per cent. of their necropsies in dogs ; from these 10 cases, 5 are classified as gliomas or ganglioneuromas (one of which was situated in the cervical cord), one as choroid papilloma, four as perithelial sarcomas. Unfortunately there is no detailed description allowing a discussion of these diagnosis. Whether the extremely high percentage they observed will be confirmed in the future or not, the relative frequency of gliomas in the dog seems already established. According to Grün (1936), there even seems to be a predominance for certain races (Boston terriers, English setters, etc.). In addition to dogs, horses and chickens (see Jungherr and Wolf, 1939) have been frequently found to harbour gliomas. On the other hand, they must be extremely rare in mice (Slye, Holmes and Wells, 1931), and certainly are not frequent in 
monkeys.* Scherer has not seen a single case on 152 necropsies of monkey brains. From Fox's (1923) monograph as well as from Hamerton's (1934-1938) reports, it would seem that captive wild animals only rarely show brain tumours. However, systematic researches on this question are needed. Jungherr and Wolf (1939) give a complete, critical, and very comprehensive review of the whole literature and try to recognize, from the mostly very poor histological descriptions, which tumour type was present. They have the impression also that in animals the groups of astrocytoma and glioblastoma are more frequent than other varieties. They give the first detailed description of a definite type of lobulated, multiple brain tumours rich in connective tissue, but predominantly formed by astrocytes, which seem to be characteristic of the chicken. Comparative pathology of gliomas is only at its beginning, but its first statements are already important for experimental glioma research.

Since the discovery of the modern carcinogenetic agents numerous investigators used them in order to obtain experimental gliomas, and most of them without success. Some of these failures have been published (Oberling, Guérin and Guérin, 1936 ; Askanazy, 1937 ; Bertrand and Grüner, 1938 ; Peers, 1939), many have not, as for instance the author's personal experiments on 70 white rats and four dogs. Weil (1938) published what he considered as being experimental gliomas in white rats, but his description and illustrations make it unlikely that the obtained tissue proliferations were real neoplasms. Finally, Seligman and Shear (1939) obtained by intracerebral implantation of pellets of methylcholantherene in 20 male $\mathrm{C}_{3} \mathrm{H}$ mice, 11 gliomas and two fibrosarcomas after 8 to 17 months. The high percentage of positive cases and the absence of spontaneous brain tumours in mice exclude any doubt about the causal relationship with the carcinogenetic agent. Description and illustrations make it absolutely sure (1) that undoubted neoplasms of sometimes enormous size were obtained, (2) that most of them showed a morphology identical with human " gliomas," and (3) that different histological types are represented. From the illustrations there is no doubt that tumours from glioblastoma and from astrocytoma type have been produced, while some of the other cytological diagnoses (made by Alexander) are not supported by the illustrations. However, this has merely a secondary interest. The essential fact is the proof that typical gliomas can be provoked by carcinogenetic agents. This discovery will be a turning-point of glioma research : it marks the end of the fanciful ætiological speculations about " congenital malformations," for the proof is established that gliomas can be produced at will in an animal which develops no spontaneous gliomas. Whether the mouse brain contains "embryonal cell rests" or not, they never do form tumours without methylcholantherene. This does not exclude the coexistence of constitutional or racial factors ; their existence seems to be indicated both by the great differences in the spontaneous occurrence of gliomas observed in different animals and by the failures of the attempts to produce them in rats. So far, comparative pathology and experi-

* The literature contains a short paper about a gliosarcoma in one Cercopithecus Anubis (Sellheim, 1936), but there is no sufficient description to judge whether this was a glioma or not. 
mental production of gliomas only prove that gliomas, as well as all other neoplasms, must have different causes and rise only by a concatenation of events. The enormous importance of Shear and Seligman's discovery is to open the way to a systematic experimental glioma research. One may reasonably hope that a comprehensive and systematic use of this discovery and perhaps also of tissue culture, no longer impeded by merely histological and " histogenetic" problems, will bring the solution of many pathogenetic, ætiological, and even therapeutic problems which could not be solved by morphological methods alone.

\section{Conclusions}

The historical evolution and the actual stage of the pathology of gliomas give worthwhile indications for future glioma research. It is obvious that the pathology of gliomas is far from being established and that problems of pathogenesis and ætiology could not be seriously studied until now because of the lack of adequate methods. The evolution of glioma research shows clearly that unilateral investigations on cellular aspects, if detached from the other morphological aspects of gliomas, lead to confusion and to arbitrary classifications in contradiction with the facts. Two main purposes and the appropriate ways for their solution are clearly indicated to future investigators.

The first is the creation of a modern pathology of gliomas by a careful and complete objective description of facts independent from doctrines and preconceived classifications. A natural classification will necessarily be the final result when all the morphologic properties of a sufficient number of gliomas shall have been studied in a really complete manner. No biopsy material can be used for these studies. This pathology and a final natural classification of gliomas are greatly needed by both pathologist and clinician. They also have to furnish solid bases and exactly formulated problems for experimental work.

The second main purpose of future glioma research has become realizable by the recent production of experimental gliomas by carcinogenetic agents. The numerous pathogenetic and ætiological problems of glioma pathology cannot any longer be studied only with morphological methods, inadequate for their'solution. They ought to be attacked by the systematic application of the method of experimental gliomas, perhaps in combination with tissue culture and comparative pathology.

\section{REFERENCES}

Abernethy (1804). Surgical Observations (quoted after Virchow).

Alpers, B. J., and Rowe, S. N. (1937). Amer. J. Cancer, 30, 1.

Alpers, B. J., and Watts, J. C. (1935). Arch. Neurol. Psychiat., Chicago, 34, 1250.

Alpers, B. J., and Yaskin, J. C. (1939). Ibid., 41, 435.

Angyan, J. von (1912). Z. ges. Neurol. Psychiat., 8, 1.

Askanazy, M. (1937). Wien. klin. Wschr., No. 21.

(1938). Schweiz. med. Wschr., 68, 1154.

Ask-Upmark, E. (1938). Acta med. scand., 94, 392.

Baasch, E. (1937). Schweiz. Arch. Neurol. Psychiat., 39, 26.

Baggenstoss, A. H., and Love, J. G. (1939). Arch. Neurol. Psychiat., Chicago, 41, 1187.

Bailey, P. (1924). Ibid., 11, 1. 
Bailey (1927a). Bull. Johns Hopk. Hosp., 40, 354.

(1927b). Arch. Path. Lab. Med., 4, 871.

- (1930). Amer. J. Path., 6, 125.

(1932a). Arch. Neurol. Psychiat., Chicago, 27, 1290.

(1932b). "Cellular Types in primary Tumors of the Brain" : In Cytology and Cellular Pathology of the Nervous System. Hoeber, New York, 3, 903.

(1933). Intracranial Tumors. Ballière, Tindall \& Cox, London.

(1935). Acta Neuropath., in honorem Lud. Puusepp, 60, 199.

(1938). J. belge Neurol., 38, 760.

Bailey, P., and Bucy, P. C. (1929). J. Path. Bact., 32, 795.

(1930). Acta Psychiat. Neurol., 5, 439.

Bailey, P., and Cushing, H. (1925). Arch. Neurol. Psychiat., Chicago, 14, 192.

(1926). Tumors of the Glioma Group. Lippincott, Philadelphia.

Bailey, P., and Ectors, L. (1938). Rev. Neurol., 70, 459.

Bailey, P., and Ley, A. (1934). Archivos de Neurologia, 14, 1.

Bannwarth, A. (1935). Arch. Psychiat. Nervenkr., 103, 471.

Belloni, G. B. (1934). Riv. Neurol., 7, 1.

Beneke, R. (1932). Mschr. Unfallheilk., 39, 49.

Berblinger, W. (1926). "Die Glandula pinealis" : in Henke and Lubarsch, Handbuch der speziellen Pathol. Anatomie. Springer, Berlin, vol. 8, 681 .

Bergstrand, H. (1932a). Acta pathol. microbiol. scand., Suppl. XI, 100. (1932b). Virchows Arch., 287, 538.

(1932c). Ibid., 287, 797 .

(1937). Ibid., 299, 725.

Bertrand, I., and Gruner, J. (1938). C. R. Soc. Biol., Paris, 128, 637.

Bertrand, I., and Medakowitch, G. (1922). Ann. Méd., 11, 509.

Bertha, H. (1939). Z. ges. Neurol. Psychiat., 167, 593.

Bielschowsky, M. (1915). J. Psychol. Neurol., 21, 253. (1924). Ibid., 30, 167.

Bodechtel, G., and Döring, G. (1938). Z. ges. Neurol. Psychiat., 161, 166.

Bodechtel, G., and Schüler, K. (1937). Dtsch. Z. Nervenheilk., 142, 85.

Borst, M. (1902). Die Lehre von den Geschwülsten. Wiesbaden.

Brandt, M. (1934). Verhandlungen der Dtsch. Path. Gesellschaft, 27, 39.

Buckley, R. C. (1929). Amer. J. Path., 5, 467. (1930). Arch. Pathol., 9, 779.

Buckley, R. C., and Eisenhardt, L. (1929). Amer. J. Path., 5, 659.

Bucy, P., and Gustafson, W. A. (1939). Amer. J. Cancer, 35, 327.

Burns, J. (1800). Dissertation on Inflammation (quoted after Virchow).

Cairns, H., in Cushing's Tumeurs intracrâniennes (1937). Masson et Cie., Paris.

Cairns, H., and Russell, D. S. (1931). Brain, 54, 377.

Carmichael, E. A. (1928). J. Path. Bact., 31, 493.

Cassirer, R., and Lewy, F. H. (1923). Z. ges. Neurol. Psychiat., 81, 290.

Ceni, C. (1899). Arch. Psychiat. Nervenkr., 31, 809.

Chiari, H. (1901). Dtsch. med. Wschr., No. 31.

Chiovenda, M. (1933). I Gliomi dell'Encephalo. Cappelli, Bologna.

Collins, R. T. (1938). Bull. neurol. Inst. N.Y., 7, 195.

Cooper, E. R. A. (1935). J. Path. Bact., 41, 259.

Cornil, L., and Robin (1922). Bull. Ass. franç. Cancer, 9.

Courville, C. B. (1936). Amer. J. Cancer, 26, 703.

(1937). Pathology of the Central Nervous System. Mountain View, California.

Cox, L. B. (1933). Amer. J. Path., 9, 939. (1934). Med. J. Austral., p. 182.

(1935). Ibid., p. 425.

Cox, L. B., and Cranage, M. L. (1937). J. Path. Bact., 45, 477.

Craig, and Kernohan, J. W. (1938). J. Amer. med. Ass., 111, 2370.

Creutzfeld, G. (1923). Arch. Psychiat. Nervenkr., 68, 485.

Cushing, H. (1930). Acta pathol. scand., 7, 1.

(1931). Surgery, Gynecology and Obstetrics, 52, 129.

(1932). Intracranial Tumors. Springfield and Baltimore.

(1937). Tumeurs intracrâniennes. Edition française, Masson et Cie., Paris.

Davidoff, L. M., and Ferraro, A. (1929). Amer. J. Psychiat., 8, 599.

Dawes, H. W. (1930). Vet. Rec., $10,717$.

De Busscher, J. (1933). J. belge Neurol., 33, 605.

Deery, E. M. (1932). Bull. neurol. Inst. N.Y., 2, 157. (1933). Ibid., 3, 599.

Echols, D. H. (1938). Arch. Neurol. Psychiat., Chicago, 39, 494.

Eisenhardt, L. (1935). Proc. Assoc. Res. nerv. ment. Dis., 16, 390.

Elsberg, C. A., Davidoff, L. M., and Brewer, E. D. (1936). J. int. Chir., 1, 1.

Elsberg, C. A., and Globus, J. H. (1929). Arch. Neurol. Psychiat., Chicago, 21, 1044. 
Elsberg, C. A., and Hare, C. C. (1932). Bull. neurol. Inst. N.Y., $2,210$.

Elvidge, A., Penfield, W., and Cone, W. (1935). Proc. Assoc. Res. nerv. ment. Dis., 16, 107.

Ewing, J. (1928). Neoplastic Diseases. Philadelphia and London.

(1936). IInd International Cancer Congress, Brussels, Reports, 2, 215.

Fischer-Wasels, B. (1932). Mschr. Unfallheik, 39, 489.

Flock, H. (1937). Frankfurt. Z. Path., 50, 289.

Foerster, O., and Gagel, O. (1931). Z. Zes. Neurol. Psychiat., 136, 335. (1934). Ibid., 151, 1. (1939). Ibid., 166, 497.

Foerster, O., Gagel, O., and Mahoney, W. (1939). Arch. Psychiat. Nervenkr., 110, 1.

Ford, F. R., and Muncie, W. (1938). Arch. Neurol. Psychiat., Chicago, 39, 82.

Fox, H. (1923). Disease in captive wild mammals and birds. Lippincott, Philadelphia, London and Chicago.

Frazier, C. H. (1936). Arch. Pediat., 53, 295.

Gagel, O. (1938). Z. ges. Neurol. Psychiat., 161, 69.

Globus, J. H. (1931). Z. ges. Neurol. Psychiat., 134, 325. (1938). Amer. J. Cancer, 32, 163.

Globus, J. H., and Silbert, S. (1931). Arch. Neurol. Psychiat., Chicago, 25, 937.

Globus, J. H., and Strauss, I. (1925). Ibid., 14, 139.

Globus, J. H., Strauss, I., and Selinsky, H. (1932). Z. ges. Neurol. Psychiat., $140,1$.

Golgi, C. (1875). Riv. sper. Freniat., 1, 65 (quoted after Bailey, 1932b). (1884). Ueber die Gliome des Gehirns. Jena.

Greenfield, J. G. (1919). Brain, 42, 29. (1936). J. Neurol. Psychopath., 16, 261. (1939). Brain, 62, 129.

Greenfield, J. G., and Robertson, E. G. (1933). Ibid., 56, 247.

Groff, R. A. (1937). Amer. J. Cancer, 29, 651.

Grün, K. (1936). " Die Geschwülste des Zentralnervensystems und seiner Hüllen bei unseren Haustieren." Vet. Med. Inaug. Diss. Berlin.

Gulotta, S. (1933). Riv. Patol. nerv. ment., 41, 38.

Hackel, W. (1934). Beitr. path. Anat. 92,510.

Hallervorden, J. (1930). "Eigenartige und nicht rubrizierbare Prozesse": In Bumke's Handb., 11, 1063.

(1936). Nervenarzt. 9, 1.

Hamerton, A. E. (1934, 1935, 1936, 1937, 1938). Proc. zool. Soc., Lond.

Hasenjäger, T. (1938). Z. ges. Neurol. Psychiat., 161, 153.

Henneberg (1897). Arch. Psychiat. Nervenkr., 30, 205.

Henschen, F. (1934). Verh. dtsch. path. Ges., 27, 8.

Hirsch, E. F., and Elliott, A. R. (1925). Amer. J. Path., 1, 627.

Hirsch, E. F., and Oldberg, E. (1938). Zbl. allg. Path. path. Anat., 69, 113.

Hjärre (1924). Skand. Vet. Tidskr., 14, 137 (quoted after Henschen). (1926). Norsk. Vet. Tidsskr., 38, 113 (quoted after Henschen).

Hollmann, W. (1936). Z. ges. Neurol. Psychiat., 156, 57.

Holtzer, P. A. F. H. (1939). Psychiat neurol. Bl. Amst., 1939. 3.

Honeyman, W. M. (1937). Amer. J. Path., 13, 1003.

Hortega, P. del Rio (1932). Arch. españ. Oncologia, 2, 411.

Ilfeld, Fr. (1936). Amer. J. Cancer, 26, 743.

Jungherr, E., and Wolf, A. (1939). Ibid., 37, 493.

Kaufmann, O. (1938). Z. ges. Neurol. Psychiat., 162, 89.

Kernohan, J. W. (1932). "Primary Tumors of the Spinal Cord and intradural Filum terminale": in Cytology and Cellular Pathology of the Nervous Sistem. Hoeber, New York, 3, 992.

Kernohan, J. W., and Fletcher-Kernohan, E. M. (1935). Proc. Ass. Res. nerv. ment. Dis., $16,182$.

Kino, F. (1935). Z. Zes. Neurol. Psychiat., 153, 680.

- (1937a). Frankfurt. Z. Path., 50, 309.

(1937b). Z. ges. Neurol. Psychiat., 160, 297.

Környey, St. (1937). Zbl. Neurochir., 2, 224.

Kredel, F. E. (1928). Amer. J. Path., 4, 337.

Kwan, S. T., and Alpers, B. J. (1931). Arch. Neurol. Psychiat., Chicago, 26, 279.

Landau, M. (1910). Frankfurt. Z. Path., 5, 469.

Levin, G. (1939). Amer. J. Cancer, 35, 22.

Lopez, F. S. (1935). Z. ges. Neurol. Psychiat., 152, 383.

Löwenberg, K., and Waggoner, R. W. (1939). Arch. Neurol. Psychiat., Chicago, 42, 842.

Lugaro, E. (1903). Riv. Patol. nerv. ment., 8, 49.

Mackay, R. P. (1935). Arch. Neurol. Psychiat., Chicago, 34, 844. (1939). Ibid., 42, 892.

Mage, J., and Scherer, H. J. (1937). J. belge Neurol., 37, 731. 
Mahon, G. S. (1936). Arch. Neurol. Psychiat., Chicago, 35, 1309.

Marburg, O. (1935). Virchows Arch., 294, 759. (1937). Wien. klin. Wschr., 44.

Martin, J. P. (1931). Brain, 54, 330.

Martin, P., and Cushing, H. (1923). Arch. Ophthal., 52, 209.

Matzdorff, P. (1924). Z. ges. Neurol. Psychiat., 91, 489.

McLean, A. J. (1936). "Intracranial Tumors" : in Bumke Foerster Handbuch der Neurologie, 14.

McLean, A. J., and Lantière, S. R. (1936). Arch. Pathol., 21, 601.

Merzbacher, and Uyeda (1910). Z. ges. Neurol. Psychiat., 1, 285.

Meyer, H. H. (1937). Virchows Arch., 300, 296.

Milks, H. J., and Olafson, P. (1936). Cornell Vet., 26, 159.

Mittelbach, M. (1934). Verh. dtsch. path. Ges., 27, 70. (1935). Beitr. path. Anat., 95.

Moore, M. T., and Stern, K. (1938). Brain, 61, 70.

Morelli, E. (1936). Pathologica, 28, 1.

Morton (1938). Amer. J. Cancer, 33, 362.

Müller, W. (1933). Z. ges. Neurol. Psychiat., 148, 469.

Muthmann, A., and Sauerbeck, E. (1903). Beitr. path. Anat., 34, 445.

Nelson, A. A. (1936). Amer. J. Cancer, 28, 1.

Neubürger, K., and Singer, L. (1926). Virchows Arch., 255.

Nevin, S. (1938a). J. Neurol. Psychiat., 1 (new series), 342. (1938b). Brain, 61, 170.

Oberling, C., Guérin, M., and Guérin, P. (1936). C. R. Soc. Biol., Paris, 123, 1152.

Ostertag, B. (1934). Verh. dtsch. path. Ges., 27, 55. (1936). Einteilung und Charakteristik der Hirngewächse. Fischer, Jena.

Peers, J. H. (1936). Amer. J. Path., 12, 911. (1939). Ibid., 15, 261.

Penfield, W. (1931). Arch. Neurol. Psychiat., Chicago, 26, 745.

Peters, G. (1935). Z. ges. Neurol. Psychiat., 153, 356.

Pines (1922). Schweiz. Arch. Neurol. Psychiat., 10, 11.

Ranke, O. (1911). Z. ges. Neurol. Psychiat., 5, 690.

Ribbert, H. (1918). Virchows Arch., 225, 195.

Rindfleisch, E. von (1886). Pathologische Gewebelehre. Würzburg.

Rosenhagen, H. (1932). Dtsch. Z. Nervenheilk., 127, 27.

Rous, P. (1936). Amer. J. Cancer, 28, 233.

Roussy, G. (1928). Ann. Anat. path. méd-chir., 5, 661.

Roussy, G., Lhermitte, J., and Cornil, L. (1924). Ibid., 1, 333.

Roussy, G., and Oberling, Ch. (1931). Atlas du Cancer : Fasc. 9 \& 10. Alcan, Paris.

Russell, D. S. (1932). J. Path. Bact., 35, 625.

(1939). Post Grad. med. J., 1939, p. 150.

Russell, D. S., and Bland, J. O. W. (1933). J. Path. Bact., 36, 273.

- (1934). Ibid., 39, 375.

Russell, D. S., and Cairns, H. (1930). Ibid., 33, 383.

Russell, D. S., Krayenbühl, H., and Cairns, H. (1937). Ibid., 45, 501.

Sahs, A. L., and Alexander, L. (1939). Arch. Neurol. Psychiat., Chicago, $42,44$.

Santha, K. von (1936). Z. ges. Neurol. Psychiat., 154, 763.

Saphir, O., and Vass, A. (1938). Amer. J. Cancer, 33, 331.

Saxer, Fr. (1902). Beitr. path. Anat., 32, 276.

Schaltenbrandt, G. (1938a). Z. ges. Neurol. Psychiat., 161, 162. (1938b). Zbl. Neurochir., 3, 169.

Scheinker, J. (1938a). Dtsch. Z. Nervenheilk., 145, 54. (1938b). Ibid., 145, 70. - (1938c). Ibid., 147, 137.

Scherer, H. J. (1933). Virchows Arch., 291, 321.

(1935a). Ibid., 294, 790.

- (1935b). Ibid., 294, 795.

- (1935c). Ibid., 294, 823.

- (1935d). J. belge Neurol., 35, 685.

- (1936a). Bull. Ass. franc. Cancer, 25, 451.

- $(1936 b)$. Ibid., 25, 470.

- (1936c). IIme Congrès int. Cancer, Bruxelles. Communications, 2, 250.

- (1937). Bull. Ass. franc. Cancer, 26, 274.

- (1938a). J. belge Neurol., 38, 1 .

- (1938b). Amer. J. Cancer, 34, 333.

- - (1938c). J. belge Neurol., 38, 783.

- $(1939 a)$. Ibid., 39, 185.

- (1939b). (In press.) Proceed. IIIrd International Cancer Congress, Atlantic City.

- (1940a). (In press.) Brain, 63. 
Scherer, H. J. (1940b). (In press.) Amer. J. Cancer.

Scherer, H. J., and De Busscher, J. (1937). J. belge Neurol., 37, 299.

Schlesinger, B. (1933). Arch. Neurol. Psychiat., Chicago, 29, 843.

Schlotthauer, C. F., and Kernohan, J. W. (1935). Amer. J. Cancer, 24, 350.

Schmincke, A. (1934). Ver. dtsch. path. Ges., 27, 43.

Schöpe, M. (1938). Z. ges. Neurol. Psychiat., 161, 177. (1939). Arch. Psychiat. Nervenkr., 109, 755.

Schwartz, Ph. (1932). Nervenarzt, 5, 449.

(1936). II. Int. Kongress Krebsforschung, Bruxelles. Mitt., 7, 257.

Schwartz, P. H., and Klauer, H. R. (1927). Z. ges. Neurol. Psychiat., 109, 438.

Seligman, A. M., and Shear, M. J. (1939). Amer. J. Cancer, 37, 364.

Sellheim, A. P. (1936). J. belge Neurol., 36, 240.

Singer, L., and Seiler, J. (1933). Virchows Arch., 287, 823.

Slye, M., Holmes, H., and Wells, H. G. (1931). Amer. J. Cancer, 15, 1387.

Smyth, G. E., and Stern, K. (1938). Brain, 61, 339.

Spatz, H. (1938). Z. ges. Neurol. Psychiat., 161, 160.

Stern, R. O. (1937). Arch. Dis. Child., 12, 291.

Stern, K. (1939). Brain, 62, 88.

Stevenson, L., and Echlin, F. (1934). Arch. Neurol. Psychiat., Chicago, 31, 93.

Stevenson, L., and Friedman, E. D. (1936). Brain, 59, 291.

Storch, H. (1889). Virchows Arch., 157, 127, 197.

Stroebe, H. (1895). Beitr. path. Anat., 18, 405.

Stumpf, R. (1911). Ibid., 51, 1.

Tönnis, W. (1938). Z. ges. Neurol. Psychiat., 161, 114.

Tooth, H. H. (1912). Brain, 35, 61.

Torkildsen, A. (1935). Acta psychiat. neurol., 10, 1, 2.

Urban, H. (1934). Frankfurt. Z. Path., 46, 486.

Virchow, R. (1863/1865). Die Lehre von den Geschwülsten, Berlin.

Voris, H. C. (1935). Arch. Neurol. Psychiat., Chicago, 34, 605.

Waggoner, R. W., and Löwenberg, K. (1937). Ibid., 38, 1208.

Walshe, F. M. R. (1931). Quart. J. Med., 24, 587.

Weil, A. (1934). A Text Book of Neuropathology. H. Kimpton, London. (1938). Arch. Path., 26, 777.

Wohlwill, F. (1910). Mitt. hamburg. St. Krankenanst., 11, 19. (1930). Z. ges. Neurol. Psychiat., 128, 587. (1935). Lisboa Medica, No. 11.

Wolf, A., and Morton, B. F. (1937). Bull. Neurol. Inst. N.Y., 6, 453.

Zeitlin, H., and Lichtenstein, B. W. (1937). Arch. Neurol. Psychiat., 38, 268. Zülch, K. J. (1937). Z. ges. Neurol. Psychiat., 158, 369. (1938). Ibid., 161, 183.

(1939a). Fortschr. Neur. Psychiat., 11, 121.

(1939b). Psychiat. Neurol. Wschr., 41, 3. 